\title{
Multimodalidade e multiletramentos: análise de atividades de leitura em meio digital
}

\section{Multimodality and multiliteracies: analysis of reading activities in a digital environment}

\author{
Vânia Soares Barbosa* \\ Universidade Federal do Piauí \\ Teresina, Piauí / Brasil \\ Universidade Estadual do Ceará \\ Fortaleza, Ceará / Brasil \\ Antonia Dilamar Araújo** \\ Universidade Estadual do Ceará \\ Fortaleza, Ceará / Brasil \\ Cleudene de Oliveira Aragão*** \\ Universidade Estadual do Ceará \\ Fortaleza, Ceará / Brasil
}

\begin{abstract}
RESUMO: Este artigo discute a promoção de multiletramentos - digital, visual e crítico - em materiais didáticos multimodais disponíveis em sítios eletrônicos. Essa discussão tem como suporte teorias que discutem multimodalidade e multiletramento, tais como a semiótica social (KRESS; VAN LEEUWEN, 2006), os multiletramentos (STREET, 2012; OLIVEIRA, 2006) e a leitura de hipertexto (XAVIER, 2005). Com o objetivo de diagnosticar uma possível congruência entre atividades de leitura de textos em língua inglesa e essas teorias, investigamos práticas pedagógicas identificadas em instruções, enunciados, conteúdos e tipos de questões propostas em cinco atividades de leitura online. Resultados preliminares apontam a não congruência entre as práticas pedagógicas e a promoção de multiletramentos.
\end{abstract}

PALAVRAS-CHAVE: Multimodalidade; multiletramentos; hipertexto.

\footnotetext{
*vaniasb@ufpi.edu.br

** dilamar@gmail.com

*** cleudenearagao@uece.br
} 


\begin{abstract}
This paper discusses multiliteracies - digital, visual, and critical in multimodal reading activities in English, which are available in websites. This discussion is grounded in theories that discuss multimodality and multiliteracy, such as social semiotics (KRESS; VAN LEEUWEN, 2006), as well as concepts of multiliteracies (STREET, 2012; OLIVEIRA, 2006) and the reading of hypertext (XAVIER, 2005). In an attempt to diagnose a possible congruence between the reading of English language texts and these theories, this study focuses on pedagogical practices identified in instructions, announcements, contents, and types of questions proposed in five online reading activities. Preliminary results show an incongruence between pedagogical practices and the promotion of multiliteracy.
\end{abstract}

KEYWORDS: Multimodality; multiliteracies; hypertext.

\title{
Introdução
}

New Literacies are diverse, dynamics, immediate, interactive, multimodal, rapidly evolving, and requisite for living and learning in the age of information and communication technologies.

Len Unsworth, "Multiliteracies and metalanguage: describing image/text relations as a resource for negotiating multimodal texts"

Os avanços nas tecnologias de comunicação e informação (TCI) têm facilitado o acesso e a circulação de informação, abrindo caminhos à comunicação. A internet certamente é um exemplo de que barreiras geográficas podem ser quebradas ainda que não haja um deslocamento espacial. Um dos efeitos dessa maior rapidez na comunicação e na circulação de informação é o crescente papel da imagem em diferentes contextos dos relacionamentos humanos (nas mensagens transmitidas pela telefonia móvel e nos emoticons utilizados em salas de bate-papo, entre tantos outros).

Por conseguinte, a facilidade de manipulação e edição de imagens e textos mediadas por ferramentas computacionais têm proporcionado a confecção de materiais didáticos cada vez mais multimodais ao permitir a inserção de diferentes modos e recursos semióticos, provocando, consequentemente, uma reorganização social do design gráfico desses materiais e da produção do conhecimento. $\mathrm{O}$ reconhecimento desse fato tem sido corroborado por Martinec e Salway (2005, p. 337), quando dizem que, “devido ao ritmo implacável da evolução das tecnologias de comunicação 
e informação, texto e imagens estão cada vez mais juntos criando textos multimodais" ", sejam esses textos impressos ou digitais.

Entretanto, se por um lado estamos diante de um contexto social no qual eventos comunicativos são realizados por meio de diferentes linguagens, com múltiplos modos e recursos semióticos, e de diferentes meios, com as tecnologias presentes cada vez mais em nosso cotidiano, por outro lado, mesmo diante da produção de hipertextos multimodais voltados para o processo de ensino-aprendizagem, não podemos afirmar que no contexto educacional as práticas pedagógicas estejam congruentes com um cenário que, a cada dia, gera novos letramentos.

Dessa forma, este trabalho se volta para materiais didáticos direcionados à leitura de hipertextos disponíveis em sítios eletrônicos de livre acesso, com o objetivo de diagnosticar a promoção de multiletramentos pela investigação de elementos, como organização do design gráfico das atividades, especialmente em função de sua constituição semiótica e computacional, da natureza das instruções e dos tipos e enunciados das questões propostas nessas atividades. Sabemos que a complexidade dos assuntos tratados requer um estudo mais aprofundado que considere diferentes aspectos, não restritos às perguntas nessas atividades, para que elas não se sobreponham à finalidade do ato da leitura. Porém, esperamos contribuir para uma reflexão acerca das potencialidades de aprendizagem a partir de hipertextos multimodais para o enriquecimento da prática da habilidade de leitura em ambientes formais e informais de aprendizagem.

\section{Multimodalidade, tecnologias e ensino}

Em nossas práticas sociais nos comunicamos não apenas por meio de palavras, mas também de sinais, gestos e imagens, entre outros recursos semióticos, configurando a comunicação como um evento multimodal que agrega diversos modos e recursos semióticos, independente do meio pela qual ela se realize - oral ou escrito, impresso ou digital. Nesses modos, a multimodalidade tem atraído a atenção de pesquisadores nas diferentes esferas do conhecimento, especialmente diante dos avanços nas TCI.

\footnotetext{
${ }^{1}$ No original, "text and images are increasingly coming together creating multimodal texts". Doravante todas as citações em língua estrangeira serão traduzidas do original, estando sob nossa responsabilidade.
} 
No campo da linguística, e mais especificadamente da linguística aplicada (LA) e da análise de discurso (AD), van Leeuwen (2011, p. 668) apresenta a multimodalidade a partir de um percurso histórico do termo partindo dos anos 1920, quando ele era utilizado por psicólogos para explicar a reação das pessoas aos diferentes sentidos - percepção sensorial -, passando pelas escolas de Praga, Paris e Estados Unidos. Nessas escolas, o termo foi sendo ampliado para adentrar no campo da linguística, até que, mais recentemente e inspirado nas ideias do britânico Michael Halliday, o termo "multimodalidade" passou a ser adotado nos estudos da LA, especialmente no que se refere à sua aplicação nos estudos de linguagem e educação.

Nesse novo cenário, multimodalidade se refere ao "uso integrado de diferentes recursos comunicativos, tais como linguagem [texto verbal], imagem, sons e música em textos multimodais e eventos comunicativos"2 (VAN LEEUWEN, 2011, p. 668). Essa integração permite que imagem e texto assumam funções diferentes, não significando uma mera substituição de um recurso por outro, ideia corroborada por diferentes teóricos, tais como Kress (1998), van Leeuwen (2011), Goldstein (2008), Martinec e Salway (2005) e Lemke (1998).

A multimodalidade, no âmbito deste estudo, é concebida de acordo com a semiótica social de Kress e van Leeuwen (2001, p. 20), para a qual a produção de sentidos é um evento social, sendo a comunicação definida como "um processo no qual um produto ou evento semiótico é tanto articulado ou produzido como interpretado ou usado"3. Entretanto, ressalta-se a afirmação desses autores de que, para que a comunicação se materialize, faz-se necessário um conjunto de ações envolvendo todos os participantes do evento comunicativo, o que, portanto, vai depender de uma comunidade interpretativa que necessita, por sua vez, comungar conhecimentos semióticos em quatro níveis: produção, distribuição, design e discurso (KRESS; VAN LEEUWEN, 2001, p. 8). Ou seja, aspectos como reprodução ou originalidade, acessibilidade, concepções ou ideias precisam ser articulados e interpretados, ainda que isso não signifique que interpretações sejam únicas, uma vez que, mesmo sendo de uma mesma

\footnotetext{
${ }^{2}$ No original, "integrated use of different communicative resources, such as language, image, sound and music in multimodal texts and communicative events".

${ }^{3}$ No original, "a process in which a semiotic product or event is both articulated or produced and interpreted or used".
} 
comunidade, indivíduos podem ter experiências diferentes que levem a interpretações diferentes.

Inserido nesse modelo, Kress (1998) o chama de "nova teoria de representação" e afirma que, no contexto da produção de textos para atividades de leitura em meio eletrônico - nosso objeto de estudo -, "a tarefa dos criadores de textos é a de uma orquestração complexa" (KRESS, 1998, p. 77), que requer habilidades de coerência textual e de articulação com os meios que a tecnologia disponibiliza, para que essa "sinfonia" (produto) seja "tocada" (usada) de maneira harmoniosa. Essas são habilidades que também não podem faltar aos "músicos" (leitores), pois eles se enquadram nos "indivíduos [que] agora são vistos como recriadores, transformadores, de conjuntos de recursos representacionais, e não mais usuários de sistemas estáveis" ${ }^{5}$ (KRESS, 1998, p. 77).

Esses aspectos ressaltam o caráter interacional da leitura e da postura de um leitor ativo que usa e manipula as informações, "em uma situação em que vários modos de representação são trazidos para composições textuais" (KRESS, 1998, p. 77). Em outras palavras, a harmonia dessa sinfonia vai depender, também, do leitor que fará a articulação e interpretação dos diversos modos (imagem e texto) e recursos semióticos (como cores, tipografia e organização textual) que compõem o texto, para produzir sentido ${ }^{7}$. A seguir, discutimos a relação multimodalidade e tecnologia para a leitura de hipertextos eletrônicos.

\subsection{Multimodalidade e tecnologias: texto e imagem na leitura de hipertextos}

Ressaltando a relação entre multimodalidade e tecnologias, Unsworth (2009, p. 377) afirma que

\footnotetext{
${ }^{4}$ No original, "the task of text-makers is that of complex orchestration".

${ }^{5}$ No original, "individuals [who] are now seen as the remakers, transformers, of sets of representational resources rather than users of stable systems".

${ }^{6}$ No original, "in a situation where multiple representational modes are brought into textual compositions".

${ }^{7}$ A identificação desse processo de produção de sentido por parte do leitor requer um estudo mais longo e aprofundado; por isso, nesta pesquisa estabelecemos os enunciados e os tipos de questões propostas nas atividades de leitura como indicativos de uma possível adequação delas a um ambiente educacional que promova multiletramentos.
} 
a internet e outras TCI têm produzido um efeito estufa, acelerando e proliferando o uso de textos multimodais e a variedade de contextos no trabalho, na sociedade, na cultura e na educação, nos quais as pessoas compartilham tais textos dentro de uma comunidade cada vez mais globalizada. ${ }^{8}$

No âmbito educacional, recursos gráficos computacionais têm facilitado a inserção de diferentes modos e recursos semióticos, tais como texto verbal (nos quais se incluem a tipografia - cores, tipos, estilo e tamanho da fonte - e a própria organização textual), imagem (estática e em movimento) e sons, na criação de hipertextos voltados para a elaboração de materiais didáticos (impressos e digitais). Entre esses materiais, destacamos os voltados para a leitura, que passa a ser então multimodal, como mostra a Figura 1, na qual diferentes modos e recursos semióticos se integram para formar uma composição multimodal voltada para a prática de leitura em língua inglesa.

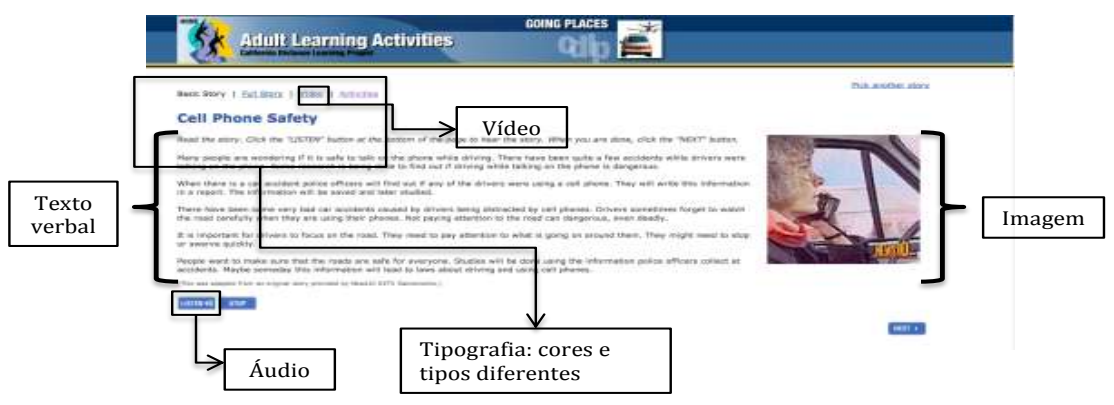

Figura 1: Atividade 4

Nesse cenário favorável à leitura de composições multimodais em meio digital, conceitos de linearidade e decodificação, por exemplo, são colocados à prova quando consideradas as potencialidades das ferramentas computacionais de agregar diversos recursos semióticos à produção do texto e de oferecer diferentes trilhas (links) para o leitor traçar seu próprio caminho

\footnotetext{
${ }^{8}$ No original, "The Internet and other ICTs have produced a hothouse effect, accelerating and proliferating the use of multimodal texts and the variety of work, social, cultural, and educational contexts in which people experience such texts within an increasingly globalized community".
} 
na construção do sentido, em um processo social e interacional ${ }^{9}$, mas não totalmente livre, pois os links colocados à sua disposição serão apenas aqueles determinados pelos produtores do texto eletrônico (XAVIER, 2005). Isso caracteriza um tipo de leitura que Xavier (2005, p. 174) chama de "self service", na qual o leitor "folheia o cardápio disponível naqueles sítios digitais, seleciona o que vai querer e, em seguida, serve-se das 'iguarias' dos hiperlinks que mais lhe apetecerem, na porção que desejar e na mesma velocidade do fluxo de pensamento". Acrescentamos a esse "cardápio de iguarias" a diversidade de modos e recursos semióticos por meio dos quais as informações são apresentadas nesses hipertextos para ressaltar o papel da multimodalidade em um processo de leitura no qual linguagens e tecnologias se relacionam hibridamente.

Observados os aspectos mencionados anteriormente quanto à "orquestração textual", essa diversidade de modos e recursos semióticos em uma mesma superfície que constitui o hipertexto, seja ele digital ou impresso $^{10}$, pode facilitar o ato de leitura e compreensão, como afirmado por Alderson (2000, p. 76) quando diz que um "texto que contenha apenas informações verbais, especialmente em letras pequenas, será não apenas intimidante, mas também mais denso e, portanto, muito mais difícil de ser processado"11 , corroborando a ideia de uma aprendizagem facilitada pela multimodalidade, também defendida por Mayer (2009), Goldstein (2008), Kress (1998) e van Leeuwen (2011), entre outros. Entretanto, nesse mesmo processo, há um risco iminente de uma dose exagerada de elementos não articulados que possa desviar a atenção do leitor e afastá-lo da compreensão do texto, desconsiderando o caráter social, político e cultural presente naquela aprendizagem, que não deve ser sobreposto por teorias centradas nas tecnologias e não no aprendiz (MAYER, 2009).

A esse respeito, Dillon (1996 apud GOMES, 2010, p. 100-101), mesmo não negando o impacto que o hipertexto possa ter na educação, se

9 Não exclusiva de um meio ou gênero. Narrativas literárias, tais como As cidades invisíveis, de Italo Calvino, e O jogo da amarelinha, de Julio Cortázar, deixam o leitor livre para traçar seus próprios caminhos de leitura.

${ }^{10}$ Diferente do que é apresentado por Xavier (2005), consideramos o hipertexto não apenas como exclusivamente eletrônico, exceto para esta análise.

${ }^{11}$ Processo entendido como interação entre texto e leitor. No original, "The text that contains only verbal information, especially in small print, will be not only intimidating but also more dense and therefore much more difficult to process". 
opõe à garantia de que "a exploração de grandes quantidades de informações leve à integração dos conhecimentos [...] [e, dessa forma, à] aprendizagem”, o que seria um "afogamento do leitor no oceano de informação" - ideia apresentada e, ao mesmo tempo, contestada por Xavier (2005, p. 179), que coloca apenas a qualidade da informação como pré-requisito para a inserção de uma grande quantidade de informação nas composições hipertextuais. Esses posicionamentos, ainda que discordantes, apenas ratificam a necessidade de que a dose de informações apresentadas não ultrapasse os limites da coerência textual.

Entretanto, a despeito do fato de que estamos diante de uma inquestionável e crescente visualização de materiais didáticos, atestada por pesquisas tais quais as realizadas por Unsworth, Thomas e Bush (2004) e por Bezemer e Kress (2009), questiona-se o acompanhamento desses avanços pelas práticas pedagógicas, que não parecem estar "adequadamente acomodadas aos textos multimodais"12 (UNSWORTH, 2009, p. 398) tampouco às novas tecnologias e, portanto, limitam-se à repetição de metodologias tradicionais nas quais o texto verbal continua sendo dominante.

Esses aspectos são especialmente observados, nesse caso, quando consideradas as questões das atividades de leitura em meio digital, como as de compreensão, que têm suas respostas condicionadas exclusivamente às informações verbais, o que pode levar o leitor a encarar o texto como linear e a imagem apenas como apêndice ilustrativo do texto (OLIVEIRA, 2006). A esse respeito, Goldstein (2008, p. 4) alerta para o fato de que "estas imagens estão sendo usadas como suporte a textos escritos que continuam a proporcionar o principal foco de nossas atenções em sala de aula"13.

No caso especifico deste estudo, situações como essas indicam a negação do potencial da multimodalidade na produção do sentido, em favor de um aspecto visual meramente atrativo da atividade de leitura, uma vez que o leitor não é convidado a integrar texto e imagem e demais modos e recursos semióticos, exceto quando eles apenas repetem as informações contidas no

\footnotetext{
${ }^{12}$ No original, "The first concerns renovating current pedagogic practices that do not adequately accommodate multimodal texts".

${ }^{13}$ No original, "these images are used as a support to written texts which continue to provide the main focus of our attention in class".
} 
texto verbal em outro modo ou suporte ${ }^{14}$. Para Unsworth (2009), é certo que nas práticas educacionais haja um consenso a respeito da prominência das imagens, como também é certo que uma metalinguagem comum a respeito de como a produção de sentido é construída e reconstruída, por meio dos diversos recursos semióticos que encontramos ao nosso dispor, se faz necessária para enriquecer e facilitar a aprendizagem. Entendemos que essa metalinguagem constituiria o convite a que nos referirmos, além de contribuir para o empoderamento da multimodalidade, devolvendo à imagem o papel que ela sempre exerceu: o de produzir significados.

Com relação às tecnologias, questões semelhantes às do meio impresso, com perguntas, em sua maioria, de múltipla escolha e verdadeiro ou falso, contrariam o que Coracini (2005, p. 34) espera do hipertexto ao afirmar que "a participação do leitor pode ser maior ainda quando livros eletrônicos para fins pedagógicos lhe dão a possibilidade de recortar e colar trechos, sublinhar passagens, pôr na memória páginas ou escrever nas margens", e, ainda, de que a interatividade tecnológica que caracterizaria a leitura em tempos de novas tecnologias, segundo a mesma autora, implica "a noção de um dispositivo capaz de respostas diferenciadas em reação a uma intervenção humana" (CORACINI, 2005, p. 34). Nesse último caso, ainda que a interatividade do leitor com a máquina e o texto sejam condições para a realização da atividade, o fato de que apenas uma resposta seja esperada e esteja correta para essas questões tira do leitor a possibilidade de diferentes interpretações.

A probabilidade de que a relação entre multimodalidade e ferramentas computacionais para produção de materiais didáticos, especificamente de atividades de leitura em meio digital, não tenha suas potencialidades de reorganizar toda uma produção de sentido em eventos comunicativos inseridas nas práticas pedagógicas observadas naquelas atividades, indica o alerta de Kress e van Leeuwen (2006) de que a educação produz cidadãos não letrados quando prioriza informações verbais em vez de ensiná-los a produzir e ler textos que combinem os diversos modos, ou seja, não promovem multiletramentos que atendam às exigências desse novo contexto social no qual tecnologias e imagens passam a fazer, cada vez mais, parte do cotidiano daqueles cidadãos, usuários daqueles materiais didáticos.

\footnotetext{
${ }^{14}$ É o caso de atividades que disponibilizam o mesmo texto verbal em áudio; ainda assim, esses dois modos produziriam sentidos diferentes.
} 


\section{Multiletramentos}

O termo multiletramentos surgiu a partir das discussões do New London Group ${ }^{15}$ a respeito do futuro das práticas pedagógicas em relação às mudanças sociais e culturais resultantes dos efeitos da globalização e do crescente avanço das TCI. Esse cenário gera demandas por novos letramentos, que vão além das habilidades de ler e escrever, e, ainda, não ficam restritos ao campo das linguagens, mas envolvem o domínio e a capacidade de desempenhar diferentes habilidades e competências, adentrando, cada vez mais, os contextos sociais, políticos e culturais, portanto, não mais restritos ao âmbito educacional. Ele gera também uma adequação etimológica do termo que não o limita à alfabetização (KLEIMAN, 1995; 2005; SOARES, 2006; CASSANY; CASTELLA, 2010), o que significaria manter uma ligação exclusiva com a linguagem verbal e, logo, contrária aos pressupostos da semiótica social e da multimodalidade, com que os participantes do grupo mantinham afinidades.

Assim, mesmo diante do alerta de Street (2012) para o risco de reificar o letramento de acordo com a forma ou o canal, adotamos o termo multiletramentos como o ideal para abrigar e explicar o impacto de todo esse conjunto de práticas sociais, domínios e usos dos diferentes códigos de linguagem e tecnologia. Sob o guarda chuva dos multiletramentos, destacamos o letramento digital, o letramento visual e o letramento crítico, não como meios excludentes ou interdependentes, mas dentro de um contexto híbrido que permite que eles estejam diretamente inter relacionados, por entendermos que eles se inserem diretamente em nosso objeto de estudo. É sobre cada um desses letramentos que versaremos a seguir.

\subsection{Letramento digital}

Como temos dito, não há como negar que avanços nas TCI têm proporcionado mudanças consideráveis em nossa sociedade em diferentes aspectos, tais como pessoal, social, cultural e educacional. Entretanto,

\footnotetext{
${ }^{15}$ Grupo formado por dez acadêmicos dos Estados Unidos (Courtney Cazden, James Gee e Sarah Michaels), Reino Unido (Norman Fairclough e Gunther Kress) e Austrália (Bill Cope, Mary Kalantzis, Allan Luke, Carmen Luke e Martin Nakata). A não tradução se justifica por uma melhor identificação do grupo.
} 
especialmente com relação à educação, ainda que muito tenha sido discutido a esse respeito, estima-se que haja um longo caminho até que se possa assegurar um processo de ensino-aprendizagem mais profícuo em consequência da utilização dessas tecnologias. Teóricos, tais como Snyder (1998), van Leeuwen (2011), Kress (1998) e Mayer (2009), ao discutirem hipertexto e multimodalidade, não deixam de chamar a atenção para o fato de que não são simplesmente a existência e a disponibilidade da tecnologia que garantem uma aprendizagem facilitada, tampouco apenas sua presença no ambiente educacional, pois é preciso saber o que fazer com ela, antes de qualquer coisa.

De acordo com Snyder (1998, p. 125), apesar da grande euforia com que foram recebidos os primeiros computadores nas escolas, nos anos 1970, e da crença de que "a tecnologia por si só iria alterar práticas sociais e culturais" "16 não foi possível atribuir uma melhora efetiva no processo de escrita, por exemplo, unicamente ao uso dos computadores. Mayer (2009) faz uma rápida retrospectiva das abordagens centralizadas nas tecnologias educacionais para mostrar que, assim como as promessas de revolução contidas na previsão de Thomas Edison de que "o filme esta[ria] destinado a revolucionar nosso sistema educacional e, em alguns anos, ir[ia] substituir consideravelmente, se não totalmente, o uso de livros didáticos" ${ }^{17}$ (CUBAN, 1986 apud MAYER, 2009, p. 10), na invenção do rádio e da televisão, por exemplo, a grande expectativa em relação aos computadores pode se tornar apenas a repetição de um círculo no qual já estamos acostumados a atuar, uma vez que,

Em vez de adaptar tecnologia para atender às necessidades de seres humanos aprendizes, seres humanos foram forçados a se adaptar às exigências de tecnologias de ponta. [...] $\mathrm{O}$ foco era em dar às pessoas $\mathrm{O}$ acesso à tecnologia mais recente, ao invés de ajudá-las a aprender com o auxílio da tecnologia. ${ }^{18}$ (MAYER, 2009, p. 12).

\footnotetext{
${ }^{16}$ No original, "the technology itself would alter social and cultural practices".

17 "the motion picture is destined to revolutionize our educational system and that in a few years it will supplant largely, if not entirely, the use of textbooks" (CUBAN, 1986, apud MAYER, 2009, p. 10).

18 "Instead of adapting technology to fit the needs of human learners, humans were forced to adapt to the demands of cutting-edge technologies. [...] The focus was on giving people access to the latest technology rather than on helping people to learn through the aid of technology" (MAYER, 2009, p. 12).
} 
Longe de uma advocacia contrária à utilização das TCI como ferramenta educacional, tais posicionamentos ressaltam a necessidade de que a tecnologia seja discutida como um meio, não um fim, e nos remetem ao letramento digital como condição diretamente relacionada à capacidade de os indivíduos utilizarem as tecnologias digitais em ambiente educacional com o objetivo de facilitar o processo de ensino-aprendizagem. Dessa forma, o entusiasmo inicial com que são recepcionadas as novas invenções tecnológicas deve abrir espaço para reflexões sobre tecnologias como ferramentas de ensino pautadas em ideias que assegurem uma inclusão digital em todos os aspectos, e não um uso indiscriminado e sem um propósito definido. Mais que ter conhecimento de suas potencialidades, é preciso que os agentes do processo de ensino-aprendizagem - professores e alunos - sintam-se capacitados a utilizá-las nos mais diversos ambientes de aprendizagem.

Em uma compilação das diferentes concepções apresentadas por Lobo Sousa, Araújo e Pinheiro (2009, p. 118), letramento digital, no âmbito desta pesquisa, inclui as capacidades de ler e escrever na tela (RIBEIRO, 2006 apud LOBO SOUSA; ARAÚJO; PINHEIRO, 2009) e de localizar, filtrar e avaliar informações para construir sentidos em textos multissemióticos (BUZATO, 2003, apud LOBO-SOUSA et al, 2009), além de habilidades de interação com a máquina e de reconhecimento das potencialidades que esse conjunto de experiências tem para a realização de eventos comunicativos.

\subsection{Letramento visual}

Da mesma forma que o letramento digital implica a capacidade dos usuários de utilizar as tecnologias digitais de maneira eficaz para a comunicação nas práticas sociais, culturais e educacionais, o letramento visual está diretamente relacionado ao entendimento da informação visual não apenas como um adorno da informação verbal, mas como um elemento semiótico que agrega sentido ao texto. Segundo Kress (1998), é certo que o aspecto visual está presente no texto eletrônico, seja no formato da fonte (tipo, tamanho e cor), ou no layout, por exemplo, e que as tecnologias contemporâneas de produção e edição de texto têm facilitado a combinação desses e de outros modos de representação (como imagem - estática ou em movimento -, sons e texto verbal). Segundo o autor, é também correto afirmar que a integração desses elementos depende de um processo que é tanto "um conjunto de fatores sociais, políticos, econômicos e culturais, 
quanto de desenvolvimentos representacionais/comunicacionais e tecnológicos"19 (KRESS, 1998, p. 54). Nesse sentido, podemos dizer que o letramento visual é mais um produto de uma postura social e cultural que de uma exposição quantitativa à variedade de informações visuais que as tecnologias disponibilizam, ainda que, "graças à tecnologia, nós vivemos em um mundo no qual imagens e informações visuais dominam nossas vidas diárias cada vez mais" 20 (GOLDSTEIN, 2008, p. 3), nos mais diferentes contextos sociais e culturais ${ }^{21}$.

Entretanto, em defesa de uma interação entre imagem e texto, Kress (1998 p. 66) chama a atenção para o perigo de que essa interação seja entendida erroneamente como "visualização", na qual "língua [texto escrito] e imagem 'estão fazendo a mesma coisa' [...] sendo apenas uma questão de tradução entre os dois modos [...] de um modo semiótico para outro" 22 . Nesse caso, em vez de um letramento visual que habilitaria o usuário a estabelecer as conexões necessárias entre os modos de informação, estaríamos diante de um processo tradutório de um modo para o outro. Assim, o letramento visual se insere nesse conjunto de novos letramentos diante da necessidade de devolvermos à imagem o papel de, assim como o texto verbal, produzir sentidos em eventos comunicativos.

Uma definição ampla de letramento visual o entende como "um grupo de competências que permite aos humanos discriminar e interpretar ações, objetos e/ou símbolos visuais, naturais ou construídos, que eles encontram no meio ambiente"23 (ERIC apud STOKES, 2002, p. 12); em ambientes educacionais de uma aprendizagem multimodal, "o letramento visual é a área de estudo que lida com o que pode ser visto e com como se pode

\footnotetext{
${ }^{19}$ No original, "a conjunction of social, political, economic and cultural as much as of representational/communicational and technological developments".

${ }^{20}$ No original, "thanks to technology, we live in a world in which images and visual information increasingly dominate our daily lives".

${ }^{21}$ Por exemplo, no envio de fotos e vídeos de eventos sociais e culturais transmitidos concomitantemente à sua realização, e nos mapas de GPS que acompanham os viajantes, entre muitos outros.

${ }^{22}$ No original, "language and image are 'doing the same thing' $[\ldots]$ it is a merely matter of translating between the two modes [...] from one semiotic mode to another".

${ }^{23}$ No original, "a group of competencies that allows humans to discriminate and interpret the visible action, objects, and/or symbols, natural or constructed, that they encounter in the environment".
} 
interpretar o que é visto", como afirmado por Oliveira (2006, p. 18) ao citar Pennings (SD). No contexto de nossa pesquisa e com base nessas definições, entendemos o letramento visual como a capacidade de ler, entender e utilizar informações visuais para a comunicação.

\subsection{Letramento crítico}

O letramento crítico tem sido discutido por autores tais como Newfield (2011), Almeida (2011), Janks (2012), Callow (2012) e Moreira (2013), que consideram a importância de que ele seja desenvolvido na leitura de textos multimodais. Para esses autores que corroboram as ideias de Kress e van Leeuwen (2006, p. 12) de que as imagens são investidas de ideologia, a dimensão crítica deve considerar as relações de poder presentes em qualquer texto. Para Callow (2012, p. 74), o letramento crítico oportuniza o leitor a reconhecer as escolhas e perspectivas apresentadas em um texto por determinado autor e a saber analisar os discursos implícitos sobre poder, gênero e questões sociais, políticas e culturais nos textos imagéticos.

Ler um texto na perspectiva crítica implica que o leitor, por meio de suas experiências, opiniões pessoais e visões do mundo, conseguirá perceber não só os sentidos denotativos e conotativos (CORACINI, 2005) construídos pela interação entre os diferentes modos e recursos semióticos, mas também ler o omitido - o não dito, no dizer de Oliveira (2006). Nesse sentido, Almeida (2011, p. 59) defende uma pedagogia crítica visual que "visa capacitar os alunos a ler e pensar criticamente e não apenas a reproduzir o que é lido", mas habilitá-los a interagir com o texto para interpretá lo, embora reconheça que o letramento crítico é um dos desafios da prática docente. Sendo as imagens investidas de ideologia, os materiais didáticos e a prática docente poderiam dar mais ênfase no contexto educacional para que o leitor possa compreender valores, crenças e questões sociais e culturais representadas nos textos multimodais.

\section{Considerações metodológicas}

\subsection{Descrição do material investigado}

Para esta análise, foram selecionadas quatro atividades de leitura disponibilizadas em sítios eletrônicos de livre acesso. Tendo em vista o amplo universo da World Wide Web, foram estabelecidos como principais critérios para essa seleção, além do livre acesso, o público alvo dessas atividades e o nível de proficiência esperado desses usuários. Assim, selecionamos 
atividades voltadas para leitores aprendizes com um nível de proficiência em língua inglesa a partir do intermediário, e não aquelas disponíveis como fonte de recursos didáticos destinados à apropriação tecnológica por parte dos professores para aplicação em sala de aula. Foi delimitado o espaço da atividade como campo de análise, excluindo, portanto, outros elementos que compõem as páginas, tais como anúncios, barras e menus. O Quadro 1 apresenta uma breve descrição dessas atividades ${ }^{24}$ :

\section{QUADRO 1}

Descrição das atividades selecionadas

\begin{tabular}{|l|l|}
\hline Atividade & Descrição \\
\hline $\begin{array}{l}\text { Atividade 1: Oxford and the } \\
\text { English Civil War }\end{array}$ & $\begin{array}{l}\text { Parte da série de atividades Beyond the postcard, que é composta por } \\
\text { doze atividades de leitura, das quais cinco são de compreensão e } \\
\text { sete de aprendizagem de vocabulário. }\end{array}$ \\
\hline Atividade 2: A hotel brochure & $\begin{array}{l}\text { Série composta por dez atividades de leitura, todas de compreensão, } \\
\text { por meio de questões em formato de quir, conforme descritas no } \\
\text { próprio site. }\end{array}$ \\
\hline Atividade 3: Black English & $\begin{array}{l}\text { Série de atividades agrupadas de acordo com os temas "história", } \\
\text { "educação" e "juventude". São 36 atividades para cada tema, com } \\
\text { perguntas que mesclam aprendizagem de vocabulário, gramática e } \\
\text { compreensão leitora. }\end{array}$ \\
\hline Atividade 4: Cell phone safety & $\begin{array}{l}\text { Parte da série Adult learning activities, cujas atividades são apresentadas } \\
\text { em doze áreas temáticas, podendo uma mesma atividade aparecer } \\
\text { em diferentes grupos. As questões envolvem aprendizagem de } \\
\text { vocabulário, compreensão leitora, e transferência (quando o leitor } \\
\text { é convidado a refletir sobre o assunto). }\end{array}$ \\
\hline
\end{tabular}

Fonte: autoria própria

\subsection{Questões de pesquisa e procedimentos de análise}

Visando a uma melhor clareza e ordenação das ideias propostas, estabelecemos as seguintes perguntas, que nortearam esta análise, em termos

\footnotetext{
${ }^{24}$ Apresentamos nos anexos screenshots das atividades. Entretanto, para facilitar o entendimento das análises, sugerimos que elas sejam acessadas diretamente de seus endereços eletrônicos, com exceção das atividades 2 e 3, cujo domínio está expirado. Atividade 1: <http://www.bbc.co.uk/worldservice/learningenglish/multimedia/btp/ oxford/oxford_text.shtml>.

Atividade 4: <http://www.cdlponline.org/index.cfm?fuseaction=activity1\&topicID $=8 \&$ story $\mathrm{ID}=147>$.
} 
gerais: I. Quais os principais modos e recursos semióticos presentes nessas atividades? Para responder a essa pergunta, serão considerados como modo o texto verbal e a imagem estática, sendo o áudio (texto oral) e o vídeo (imagem em movimento) seus suportes, respectivamente; como recursos semióticos, cores e tipografias. II. Quais são os tipos de questões nessas atividades? Serão consideradas as seguintes tipos: 1 . de múltipla escolha; 2 . de verdadeiro ou falso; 3 . de preenchimento de lacunas; 4 . de preenchimento de lacunas com múltipla escolha; 5 . de produção textual; 6. de feedback para as respostas (link). Com relação ao letramento digital: III. Quais ações de interatividade com a máquina estão inseridas nessas atividades? Para responder a essa pergunta, determinamos as seguintes ações: 1. rolagem da página; 2. acesso a outros links; 3 . cliques para escolha de alternativas de respostas; 4 . movimentos com o mouse para mover palavras ou objetos; 5 . produção textual; 6. impressão do texto. Quanto ao letramento visual: IV. É possível afirmar uma promoção explícita desse letramento? Essa pergunta será respondida com a observação das instruções e enunciados das questões e de suas respectivas propostas de respostas, além de com a apresentação das informações em diferentes modos e recursos semióticos. Finalmente, com relação ao letramento crítico: V. Há, nas questões dessas atividades, alguma pergunta que leve o leitor a reconhecer diferentes discursos presentes no texto imagético e a discutir questões sociais, políticas e culturais? Essa pergunta será respondida exclusivamente pela observação dos enunciados das atividades propostas.

\section{Apresentação e discussão dos resultados}

Cientes da complexidade dos assuntos apresentados, ao selecionarmos apenas atividades cujo público alvo é, principalmente, o leitor autônomo como usuário, diferentemente daquelas que estão à disposição de professores como recursos didáticos a ser utilizados em ambientes formais de aprendizagem, delimitamos as instruções e os enunciados das questões como única fonte de metalinguagem para uma possível promoção explícita dos multiletramentos. Entretanto, sabemos que essas instruções e questões, apresentadas em texto verbal, não são os únicos participantes do processo de produção de sentido das atividades analisadas, pois, se assim fosse, teríamos a negação de todo o potencial da multimodalidade e das novas tecnologias nos eventos comunicativos e no contexto educacional apresentado que, como mostraremos a seguir, se fizeram presentes em todos os textos analisados. 


\subsection{Multimodalidade e questões}

Ao observamos os modos semióticos presentes nas atividades de leitura em meio digital, constatamos que, ainda que a imagem esteja presente em três das quatro atividades analisadas, como mostra o Quadro 2, o texto verbal ocupa o maior espaço no layout dessas atividades, chegando mesmo a ser o único modo em uma das atividades analisadas (Atividade 3, Anexo 3). Tal constatação indica a continuidade da supremacia da linguagem verbal sobre a imagem em ambientes de aprendizagem, também alertada por Metros e Woolsey (2006), Kress et al. (2014), Barbosa e Araújo (2014) e Adami (2016), entre outros, o que não significa, de forma alguma, que texto e imagem estejam dizendo a mesma coisa.

\section{QUADRO 2}

Principais modos e recursos semióticos

\begin{tabular}{|l|l|l|}
\hline \multirow{2}{*}{ ATIVIDADES } & DESCRIÇÃO & \multicolumn{2}{|c|}{ Recursos semióticos } \\
\cline { 2 - 3 } Atividade 1 & Modos semióticos & $\begin{array}{l}\text { Cores: destaque de títulos, subtítulos, links e } \\
\text { backgrounds; } \\
\text { Tipografia: cores e tamanhos de fontes diferentes para } \\
\text { destacar elementos textuais e palavras em negrito. }\end{array}$ \\
\hline Atividade 2 & Texto e uma imagem & $\begin{array}{l}\text { Cores: destaque do texto principal em relação ao restante } \\
\text { da página (background) e fonte para indicar link; } \\
\text { Tipografia: tamanhos diferentes de fonte para destacar } \\
\text { elementos textuais. }\end{array}$ \\
\hline Atividade 3 & Texto & $\begin{array}{l}\text { Cores: diferenciação de elementos textuais; } \\
\text { Tipografia: estilo, cores e tamanhos diferentes de fonte } \\
\text { para destacar elementos textuais e palavras; negrito } \\
\text { para destacar as questões. }\end{array}$ \\
\hline Atividade 4 & $\begin{array}{l}\text { Texto (oral e escrito) e } \\
\text { imagem (estática e em } \\
\text { movimento) }\end{array}$ & $\begin{array}{l}\text { Cores: destaque de títulos, subtítulos e links; } \\
\text { Tipografia: estilos e tamanhos de fonte diferentes para } \\
\text { destacar elementos textuais e informações. }\end{array}$ \\
\hline
\end{tabular}

Fonte: autoria própria

Confirmando o que foi dito por Martinec e Salway (2005, p. 337) a respeito da criação de textos multimodais em função do ritmo acelerado das tecnologias, também em relação aos principais ${ }^{25}$ recursos semióticos

${ }^{25}$ Não em ordem de importância, mas de generalidade. 
utilizados, observamos o potencial da multimodalidade em eventos comunicativos por meio do uso variado de cores e tipografias para realização de diferentes tipos de informação, inclusive para a demarcação do espaço do texto verbal e a sinalização de palavras julgadas importantes para a leitura do texto.

Entretanto, se por um lado podemos reafirmar as facilidades que as ferramentas computacionais proporcionam para a confecção de materiais didáticos multimodais, por outro lado, ao considerarmos as questões propostas nesses materiais, verificamos que elas são semelhantes aos do meio impresso, como mostra o Quadro 3, sendo a principal diferença entre os meios a possibilidade de um feedback instantâneo em relação à resposta considerada correta pelos produtores das atividades. No caso da Atividade 4, o feedback é uma condição para que o leitor dê continuidade à tarefa. Essa possibilidade não está disponível na Atividade 3 (Anexo 3) pelo simples fato de que ela, definitivamente, só se diferencia em relação ao suporte, uma vez que não é possível respondê-la na própria página. Além disso, ao considerarmos os tipos de perguntas, observamos o total controle da leitura por parte dos produtores das atividades, que não oferecem ao leitor outras opções de respostas que não seja a pré-determinada, mesmo em casos de produção de texto, nos quais as respostas devem ser retiradas do texto principal. Observaram-se, ainda, casos nos quais as respostas eram obtidas em parágrafos subsequentes, caracterizando a promoção de uma leitura linear.

\section{QUADRO 3}

Tipos de questões

\begin{tabular}{|l|l|l|l|l|}
\hline Tipos de questões & Atividade 1 & Atividade 2 & Atividade 3 & Atividade 4 \\
\hline 1. Múltipla escolha & - & $\mathrm{x}$ & - & - \\
\hline 2. Verdadeiro ou falso & $\mathrm{x}$ & $\mathrm{x}$ & - & - \\
\hline 3. Preenchimento de lacunas & - & - & $\mathrm{x}$ & - \\
\hline $\begin{array}{l}\text { 4. Preenchimento de lacunas com múltipla } \\
\text { escolha }\end{array}$ & - & - & - & $\mathrm{x}$ \\
\hline 5. Produção textual & - & - & $\mathrm{x}$ & $\mathrm{x}$ \\
\hline 6. Feedback para as respostas (link) & $\mathrm{x}$ & $\mathrm{x}$ & - & $\mathrm{x}$ \\
\hline
\end{tabular}

Fonte: autoria própria 


\subsection{Multimodalidade e letramento digital}

Ao considerarmos as ações de interatividade requisitadas para que o leitor possa realizar as atividades, constatamos o risco iminente de que tecnologias estejam sendo usadas apenas como suporte digital que pouco se diferencia do suporte impresso. Características observadas na Atividade 3 (Anexo 3) traduzem perfeitamente essa ideia, uma vez que, como dissemos, para realizá-la o leitor terá que optar pela impressão ou por outras alternativas que não incluem a escrita na tela da atividade. Nesse caso, já que não é possível escrever na tela, o diferencial para a leitura estaria na passagem das folhas, que agora passa a ser rolagem da página do computador/tablet/ smartphone, exceto para a Atividade 4 (Figura 1, p. 6), mas essa mesma mudança aconteceu anos atrás na passagem do rolo para o códex, embora de forma inversa, ou seja, da rolagem para a passagem das páginas ${ }^{26}$.

Ainda, sendo a ação de clicar na resposta correta a opção mais recorrente para responder as questões efetivamente, uma vez que as demais - rolagem da página e acesso a outros links - são ações para realização da atividade em geral e obtenção de informações adicionais, podemos dizer que, nesse caso, não é esperado dos usuários um letramento digital em tudo que as definições apresentadas contemplam. Tanto é que, em alguns casos, o leitor é instruído verbalmente, também, a realizar determinadas ações, por exemplo: "ao terminar a atividade, clique no botão azul". Nesse aspecto, a atividade que apresentou a maior variedade de ações foi a Atividade 4, inclusive com a possibilidade de uma leitura de self-service (XAVIER, 2005), na qual o leitor tem uma certa liberdade de escolher o tipo de questão que deseja realizar. A recorrência dessas ações é mostrada no Quadro 4.

\section{QUADRO 4}

Ações de interatividade com a máquina

\begin{tabular}{|l|l|l|l|l|}
\hline Tipos de ações & Ativ. 1 & Ativ. 2 & Ativ. 3 & Ativ. 4 \\
\hline 1. Rolagem da página & $\mathrm{x}$ & $\mathrm{x}$ & $\mathrm{x}$ & - \\
\hline 2. Acesso a outros links & $\mathrm{x}$ & $\mathrm{x}$ & - & $\mathrm{x}$ \\
\hline 3. Cliques para escolha de alternativas de respostas & $\mathrm{x}$ & $\mathrm{x}$ & - & $\mathrm{x}$ \\
\hline 4. Movimentos com o mouse para mover palavras ou objetos & - & - & - & $\mathrm{x}$ \\
\hline 5. Produção textual & - & - & - & $\mathrm{x}$ \\
\hline 6. Impressão do texto & - & - & $\mathrm{x}$ & - \\
\hline
\end{tabular}

Fonte: autoria própria

${ }^{26}$ Desconhecemos pesquisas que, até o momento da redação deste artigo, tenham identificado mudanças no ato de leitura desses diferentes suportes. 
Entretanto, essa variedade de ações não caracteriza totalmente a interatividade tecnológica (CORACINI, 2005), uma vez que, exceto para a produção textual, para as demais questões há comportamentos esperados e pré-determinados pelos produtores das atividades.

\subsection{Multimodalidade e letramento visual}

Os resultados até aqui apresentados reafirmam o potencial da multimodalidade na produção de sentido e o potencial das tecnologias na confecção de materiais didáticos multimodais. Entretanto, ao considerarmos as instruções, enunciados e conteúdos das questões propostas nas atividades analisadas, como mostra o Quadro 5, constatamos, mais uma vez, a predominância do texto verbal em relação a qualquer outro modo semiótico. Não foram encontradas perguntas que remetessem à leitura da imagem em nenhuma das atividades e, mesmo no caso da Atividade 4, na qual há instruções para ouvir o áudio e assistir ao vídeo, o que se observou foi a repetição do texto verbal, caracterizando o que Kress (1998) alertou como a simples tradução de um modo semiótico para outro - nesse caso, de um suporte para outro. Percebe-se a ausência de uma metalinguagem que promova o letramento visual do leitor e o ajude a integrar os diferentes modos e recursos semióticos nessas atividades, ainda que, como já alertamos, a utilização de cores para sinalizar links, por exemplo, seja uma forma de promoção de letramento visual, porém não feita explicitamente por meio de instruções e enunciados. Esses enunciados, como observado, direcionam a leitura daqueles hipertextos às informações verbais.

\section{QUADRO 5}

Instruções, enunciados e conteúdos das questões

\begin{tabular}{|l|l|l|}
\hline \multirow{2}{*}{ ATIVIDADES } & \multicolumn{2}{|l|}{ DESCRIÇÃO } \\
\cline { 2 - 3 } & Instruções & Enunciados e conteúdos \\
\hline Atividade 1 & $\begin{array}{l}\text { Leitura do texto verbal } \\
\text { para responder as questões }\end{array}$ & $\begin{array}{l}\text { Todas as perguntas e respostas estão diretamente } \\
\text { relacionadas ao texto verbal }\end{array}$ \\
\hline Atividade 2 & $\begin{array}{l}\text { Leitura do tex to verbal } \\
\text { para responder as questões }\end{array}$ & $\begin{array}{l}\text { Todas as perguntas e respostas estão diretamente } \\
\text { relacionadas ao texto verbal }\end{array}$ \\
\hline Atividade 3 & $\begin{array}{l}\text { Leitura do tex to verbal } \\
\text { para responder as questões }\end{array}$ & $\begin{array}{l}\text { Perguntas relacionadas ao texto (vocabulário e } \\
\text { compreensão); questões de gramática; produção } \\
\text { textual diretamente não relacionada ao texto }\end{array}$ \\
\hline Atividade 4 & $\begin{array}{l}\text { Háinstruções para cada passo } \\
\text { seguinte, em cada atividade }\end{array}$ & $\begin{array}{l}\text { Perguntas relacionadas ao texto (vocabulário, } \\
\text { ortografia e compreensão); produção textual }\end{array}$ \\
\hline
\end{tabular}

Fonte: autoria própria 


\subsection{Multimodalidade e letramento crítico}

Finalmente, constatamos que o letramento crítico pode ser desenvolvido com os letramentos visual e digital, porém as atividades analisadas mostraram que esse tipo de letramento não é promovido, uma vez que as questões não direcionam o leitor a pensar e discutir criticamente as questões históricas, sociais, políticas e culturais representadas nos diferentes modos e recursos semióticos que constituem os textos multimodais no contexto da web. Ainda, contrariando a expectativa de Almeida (2011) por uma pedagogia crítica visual, assim como já constatado em relação ao letramento visual, os enunciados das questões analisadas indicam não apenas o total controle das respostas - portanto esperando do leitor apenas a reprodução do que foi dito -, como também o condicionamento daquelas respostas à leitura do texto verbal apenas, e não ao que foi mostrado. Assim, além de uma não promoção do letramento crítico, tal posicionamento pode desviar a atenção do leitor para discursos políticos, sociais e culturais que estão embutidos na escolha das imagens para compor materiais de ensino. Como exemplo, citamos uma das duas imagens da Atividade 1 (Anexo 1), cujo texto trata da batalha que aconteceu em Oxford (Inglaterra) no século XVII entre aqueles que apoiavam o parlamento e os que apoiavam o rei. Na imagem, o que é mostrado é apenas um dos dois lados daquela batalha, sendo o outro lado omitido.

\section{Considerações finais}

Mostramos nesta análise a tendência multimodal dos materiais didáticos voltados para a prática da leitura de hipertextos eletrônicos, tendência essa facilitada pelos avanços nas TCI. Apontamos potencialidades da relação ensino-tecnologias-multimodalidade e as constatamos nas atividades selecionadas quando consideradas a sua composição textual por diferentes modos e recursos semióticos.

Quando consideradas as ações de interatividade do leitor com a máquina, verificamos similaridades nas atividades analisadas e instruções em texto verbal como forma de condução dessa interatividade, o que nos leva ao entendimento de que, a despeito das potencialidades computacionais em ambientes de aprendizagem, o letramento digital requerido para os usuários dessas atividades não ultrapassa em muito a capacidade de ler na tela - não descartando a possibilidade de uma leitura linear e não ultrapassando a leitura de compreensão, uma vez que apenas uma única 
questão convida o leitor a ir além do que foi dito no texto. Esse aspecto também foi diagnosticado ao serem consideradas as instruções e questões e, novamente, as similaridades entre as atividades indicaram que, mesmo diante de uma riqueza multissemiótica, o texto verbal continua a ocupar o maior espaço nas atividades de leitura, tanto em termos gráficos como em relação ao conteúdo, não havendo, nesse caso, a promoção explícita do letramento visual ou crítico.

Portanto, no contexto deste estudo, os resultados apresentados confirmam a falta de congruência entre a tendência multimodal dos materiais didáticos voltados para a leitura de hipertextos eletrônicos e as práticas pedagógicas, uma vez que, na ausência de uma metalinguagem comum a esse novo cenário de multiletramentos, essas práticas pedagógicas mantêm a repetição de atividades tradicionais de aprendizagem, diferenciando-se delas apenas em relação ao meio - se impresso ou digital - quando deveriam fazer uso das reais potencialidades que esse meio possui e, principalmente, deixar aberta a porta para a produção de sentido por parte do leitor, incentivando-o a integrar diferentes informações e, atuando sobre elas, criar uma série de oportunidades de participação em eventos comunicativos.

\section{Agradecimentos}

À Coordenação de Aperfeiçoamento de Pessoal de Nível Superior (Capes) e à Fundação de Amparo à Pesquisa do Estado do Piaú (Fapepi), pelo suporte financeiro para o desenvolvimento desta pesquisa.

\section{Referências}

ADAMI, E. Multimodality. In: GARCIA, O.; FLORES, N.; SPOTTI, M. Oxford handbook of language and society. Oxford: Oxford University, 2016. No prelo. ALDERSON, J. C. Assessing reading. New York: Cambridge University, 2000.

ALMEIDA, D. B. L. Multimodalidade e ensino: integrando o texto e contexto em estruturas visuais. In: BARBARA, L; MOYANO, E. (Orgs). Textos e linguagem acadêmica: explorações sistêmica funcionais em espanhol e português. Campinas: Mercado das Letras, 2011. p. 55-66.

BARBOSA, V. S.; ARAÚJO, A. D. Multimodalidade e letramento visual: um estudo piloto de atividades de leitura disponível em sítio eletrônico. Revista da ANPOLL, Florianópolis, v. 1, n. 37, p. 17-36, 2014.

BEZEMER, J.; KRESS, G. Visualizing English: a social semiotic history of a school subject. Visual Communication, New York, v. 8, n. 3, p. 247-262, 2009. 
CALLOW, J. The rules of visual engagement: images as tools for learning. Screen Education, Victoria, n. 1, p. 72-79, 2012. Disponível em: <http://search.informit. com.au/documentSummary;dn=519979938136339;res=IELHSS > Acesso em: 22 jan. 2014.

CASSANY, D.; CASTELLA, J. M. Aproximación a la literacidad crítica. Perspectiva, Florianópolis, v. 28, n. 2, p. 353-374, jul./dez. 2010.

CELL Phone Safety. California Distance Learning Project. 2011. Disponível em: <http://www.cdlponline.org/index.cfm?fuseaction= activity1\&topicID=8\&storyID=147>. Acesso em: 11 out. 2016.

CORACINI, M. J. R. F. Concepções de leitura na (pós)modernidade. In: LIMA, R. C. C. P. (Org.). Leitura: múltiplos olhares. Campinas: Mercado de Letras; São João da Boa Vista: Unifeob, 2005. p. 15-44.

GOLDSTEIN, B. Working with images: a resource book for the language classroom. Cambridge: Cambridge University, 2008.

GOMES, L. F. Hipertextos multimodais: leitura e escrita na era digital. Jundiaí: Paco Editorial, 2010.

JANKS, H. The importance of critical literacy. English Teaching - Practice and Critique, Hamilton, v. 11, n. 1, p. 150-163, May 2012.

KLEIMAN, A. B. Modelos de letramento e as práticas de alfabetização na escola. In: KLEIMAN, A. B. (Org.). Os significados do letramento: uma nova perspectiva sobre a prática social da escrita. Campinas: Mercado de Letras, 1995.

KLEIMAN, A. B. Preciso "ensinar" o letramento? Não basta ensinar a ler e a escrever? Brasília, DF: Ministério da Educação, 2005.

KRESS, G. Visual and verbal modes of representation in electronically mediated communication. In: SNYDER, I. (Ed). Page to screen: talking literacy into electronic era. New York: Routledge, 1998. p. 53-79.

KRESS, G. et al. Multimodal teaching and learning: the rhetorics of the science classroom. London: Bloomsbury, 2014.

KRESS, G.; VAN LEEUWEN, T. Reading images. London: Routledge, 2006.

KRESS, G.; VAN LEEUWEN, T. Multimodal discourse: the modes and media of contemporary communication. London: Arnold, 2001.

LEMKE, J. L. Metamedia literacy: transforming meanings and media. In: REINKING, D. et al. Hillsdale: Lawrence Erlbaum, 1998. p. 283-301.

LOBO-SOUSA, A. C.; ARAÚJO, J. C.; PINHEIRO, R. C. Letramentos que emergem da hipertextualidade. In: ARAÚJO, J. C.; DIEB, M. (Orgs.). Letramentos na web: gêneros, interação e ensino. Fortaleza: UFC, 2009. p. 111-122.

MARTINEC, R.; SALWAY, A. A system for image-text relation in new (and old) media. Visual Communication, New York, v. 4, n. 3, p. 337-71, 2005. 
MAYER, R. E. Multimedia learning. Cambridge: Cambridge University, 2009.

METROS, S. E.; WOOLSEY, K. Visual literacy: an institutional imperative. Educause review, Louisville, v. 41, n. 3, May/June 2006.

MOREIRA, H. N. As relações entre os modos visual e verbal em atividades de compreensão leitora: um estudo da multimodalidade em coleções didáticas de espanhol/língua estrangeira. 2013. Dissertação (mestrado em Linguística Aplicada) - Centro de Humanidades, Programa de Pós-graduação em Linguística Aplicada, Universidade Estadual do Ceará, Fortaleza, 2013.

NEWFIELD, D. From visual literacy to critical visual literacy: an analysis of educational materials. English Teaching - Practice and Critique, Hamilton, v. 10, n. 1, p. 81-94, 2011.

OLIVEIRA, S. Texto visual e leitura crítica: o dito, o omitido, o sugerido. Revista Linguagem e Ensino, Pelotas, v. 9, n. 1, p. 15-29, jan./jun. 2006.

OXFORD. BBC World Service. s.d. Disponível em: <http://www.bbc.co.uk/ worldservice/learningenglish/multimedia/btp/oxford/oxford_text.shtml>. Acesso em: 11 out. 2016.

SNYDER, I. Beyond the hype: reassessing hypertext. In: SNYDER, I. (Ed). Page to screen: talking literacy into electronic era. New York: Routledge, 1998. p. 125-143. SOARES, M. Letramento: um tema em três gêneros. 2. ed. Belo Horizonte: Autêntica, 2006.

STOKES, S. Visual literacy in teaching and learning: a literature perspective. Electronic Journal for the Integration of Technology in Education, Pocatello, v. 1, n.1, p. 10-19, 2002.

STREET, B. Eventos de letramento e práticas de letramento: teoria e prática aos novos estudos de letramento. In: MAGALHÃES, I. (Org.). Discursos e práticas de letramento: pesquisa etnográfica e formação de professores. Campinas: Mercado de Letras, 2012. p. 69-92.

UNSWORTH, L. Multiliteracies and metalanguage: describing image/text relations as a resource for negotiating multimodal texts. In: COIRO, J. et al (Ed.). Handbook of research on new literacies. New York: Routledge, 2009. p. 377-405.

UNSWORTH, L.; THOMAS, A.; BUSH, R. The role of images and image-text relations in group "Basic Skills Tests" of literacy for children in the primary school years. Australian Journal of Language and Literacy, Adelaide, v. 27, n. 1, p. 46-65, Feb. 2004. VAN LEEUWEN, T. Multimodality. In: SIMPSON, J. (Ed.). The Routledge handbook of applied linguistics. New York: Routledge, 2011. p. 668-682.

XAVIER, A. C. Leitura, texto e hipertexto. In: MARCUSCHI, L. A.; XAVIER, A. C. (Org.) Hipertextos e gêneros digitais: novas formas de construção de sentido. 2. ed. Rio de Janeiro: Lucerna, 2005. 


\section{ANEXO 1: Screenshot da Atividade 1}

B $\mid$ B $|C| L E A R N I N G$ ENGLISH

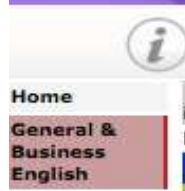

Grammar,

Vocabulary 8

Pronunciation

Quizzes

The

Flatmates

Community

For teachers

Specials

About us

Downloads
This page has been archived and is no longer updated.

Find out more about page archiving.

You are Learning English > Watch and Listen > Beyond the Postcard > in: Oxford text

Learning English - Beyond the Postcard Other cities and towns

Oxford

Oxford and the English Civil War

In the 17 th century, Oxford played an important role in Britain's civil war. The war was between those who supported Parliament and those who supported the King

Read the text below, then try and answer the questions which follow.

You can also see definitions of the vocabulary in bold.

By August 1642, it had become olear that the disagreements between the two were so severe that they would only be resolved by fighting. The king, Charles I, returning from the north, raised his standard at Nottingham, and Charles I, returning from the north, raised his standard at Nottingham, an moved towards London. After a first, somewhat inconclusive battle, Parliament, and his way was barred. So in November the King turned towards Oxford, to make that his headquarters.

WF loyal to him, one in the west and one in the north, and overwhelm London by force. But the three armies were too far apart, and it proved difficult - and in the end, impossible - to achieve his objective. The war dragged on, therefore, and the king was forced to spend much more time based at Oxford than he originally intended.

The city took on a much more military character. New College became the main magazine, for example; and cattle to feed the army were kept in the great quadrangle of Christ Church (the college which became the King's residence). So many soldiers in the streets led to so much brawling that the sale of alcohol was forbidden after nine in the evening. Oxford scarcely functioned as a university at all.

The war continued for over three years, with the King's side gradually losing ground all over the country. Eventually the advancing Parliamentary armies began to close in on Oxford from all directions; but before the net was completely tight, the King - in disguise - slipped out.

The city was fortunate in that it escaped a siege. It was clear that the King's loyal troops could not defeat the forces ranged against them, and so a

surrender, with no loss of life and little loss of honour, was negotiated. In June 1646 the last members of the King's court left Oxford.

See vocabulary

\section{Exercise - Comprehension}

Look at the statements below, according to the text are they true or false?

1: The king went to Oxford after he had defeated London

True or False :

2: The king's plan didn't work as well as he had hoped.

True or False :

3: The life of the university wasn't badly affected by the military presence in the town.

4: The king escaped from Oxford by hiding his identity.

True or False $\uparrow$

True or False :

5: After a long battle Oxford was taken by the Parliamentary armies.

True or False :

Check your answers 
ANEXO 2: Screenshot da Atividade 2

\section{Intermediate-level English Comprehension Activity}

Hasad the intermediato-level Engtinh taxt and oomplete the multiple-choice quiz underneath

To give yourself the best chanee of eveoess, reas all the tent first before attempting any of the queetions. Chock out this articie for hinta and tipe on how to improve your resading oamprehonvion akell,

To use this as a more general leaming repouroe, une s dictionary to look up any worde you don't know. To make it more dithouit, give yourseif a time limi to ariawer all the questiona. Goos wote!

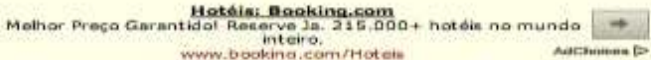

\section{A Hotel Brochure}

\begin{tabular}{|c|c|}
\hline \multicolumn{2}{|c|}{ Sea Towers Hotel } \\
\hline 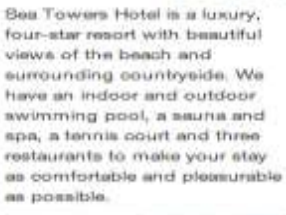 & 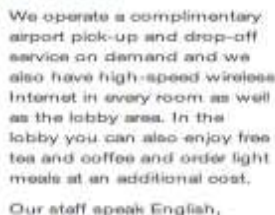 \\
\hline 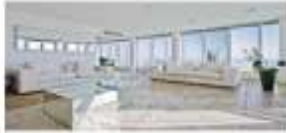 & 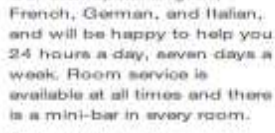 \\
\hline 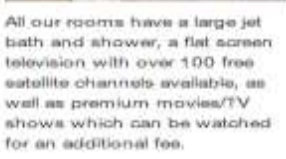 & $\begin{array}{l}\text { Plesses note that there is no } \\
\text { mmoking ariywhere in our } \\
\text { buidings or grounds, axcept } \\
\text { in the designated outside } \\
\text { smoking area. }\end{array}$ \\
\hline
\end{tabular}

\section{Quostions}

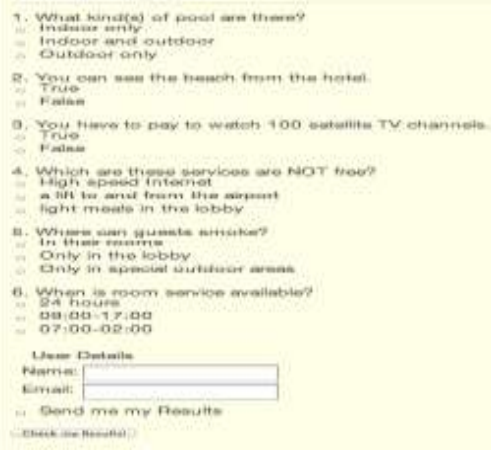


ANEXO 3: Screenshot da Atividade 3

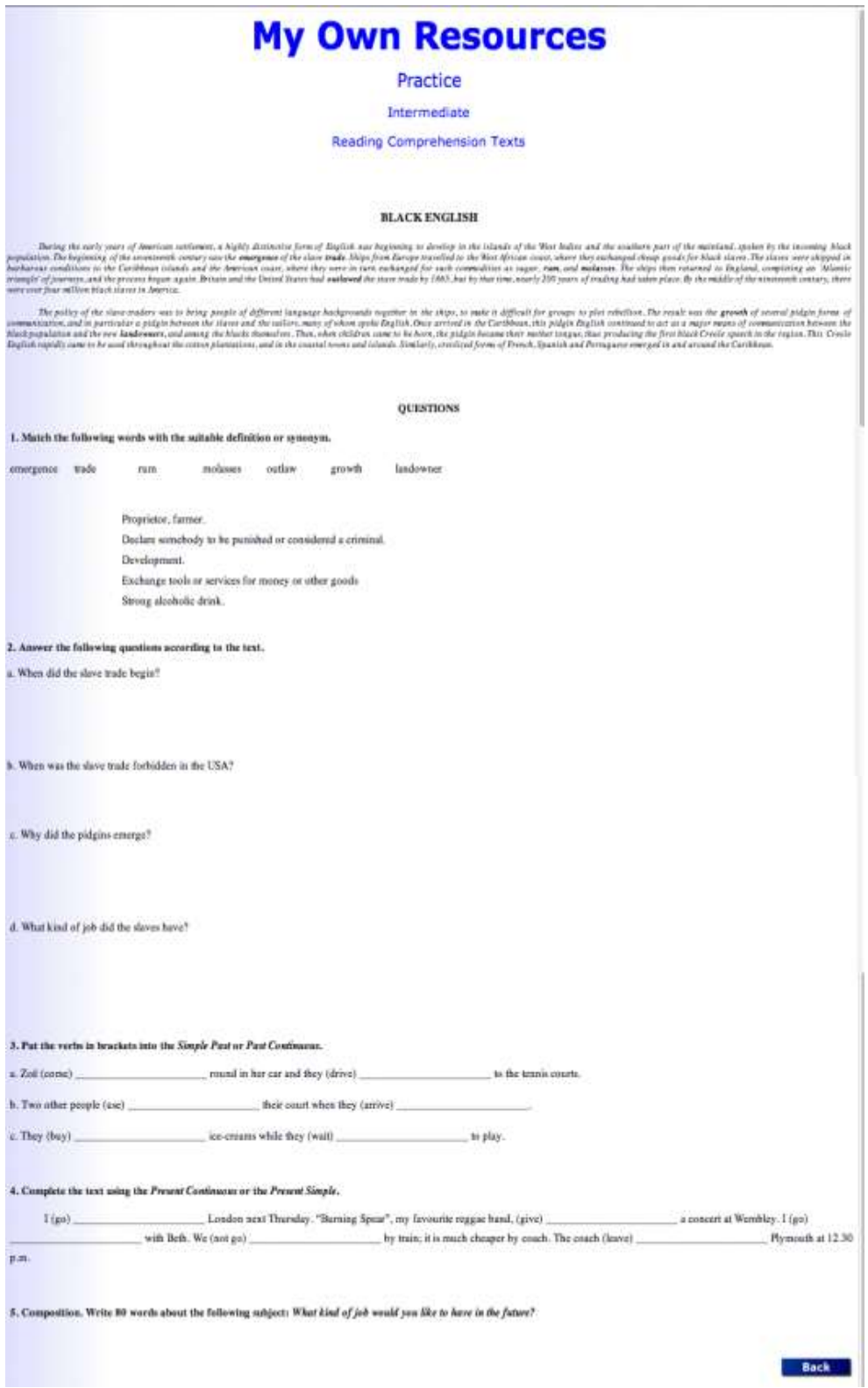


ANEXO 4: Screenshots de exemplos de questões da Atividade 4

Cell Phone Safety

Activity

Banaic story

Eull story

Video

Learn New Words

Spell a Word

Matching Game

Pick an Answer

Write an Answer

Learn More At Other Web sites
Score

Completed

SEIENGE and TECHWOLOCY

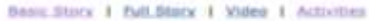

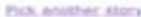

\section{Cell Phone Safety}

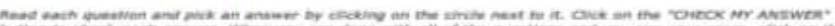

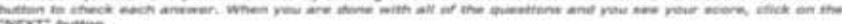

\section{Pick an Answer}

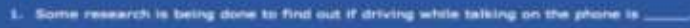

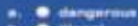

S. Q iment

a. 6 min

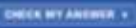

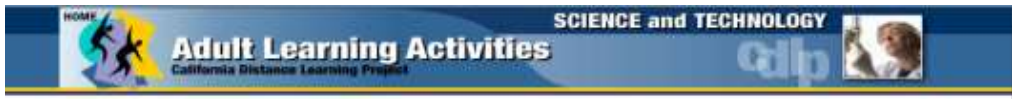

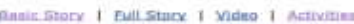

\section{Cell Phone Safety}

Mead the queation and chpe ail ansiwer in the box below. Then click on the "SAVE MY ANSWER" button. When your anvwar has been saved, dick on the *NEXT Button.

\section{Write an Answer}

De vou think that it is safe for people to taik on the phone while driving? why?

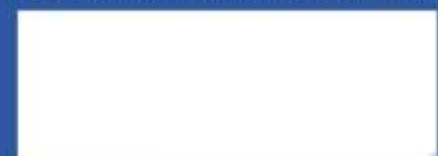

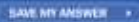

aile heveleet

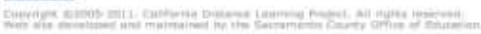

Recebido em: 27/01/2016. Aprovado em: 28/09/16 